\title{
Comparing root porosity of sunflower adventitious root segments using cross-sectioning and buoyancy method under hypoxic condition
}

\author{
Shirin Ahmadi, Akbar Mostajeran and Sanaz Shokrollahi \\ Department of Biology, Faculty of Sciences, University of Isfahan, Isfahan, Islamic Rep. of Iran. \\ Corresponding author: A. Mostajeran, E. mail: mostajerana@yahoo.com, Phone: +98-311-793 24 71, \\ Fax: +98-311-7932456
}

Received on October 3, 2012; Accepted on December 27, 2012

\begin{abstract}
Two well-known methods of root porosity measurement (i.e. buoyancy and cross-sectional) were used to evaluate the porosity of adventitious roots of 3-day hypoxia treated sunflower (Helianthus annus L.) cultivars to address the effect of hypoxia on root porosity as well as advantages and disadvantages of each method. In the first experiment, length of adventitious roots of two sunflower cultivars (CMS14 $\times$ R-864 and Hysun-33) was divided to three segments as apical, middle, and basal portions and porosity was measured via both methods. In buoyancy method, root porosities of Hysun-33 and CMS14 $\times$ R-864 cultivars were $5.12 \%$ and $6.47 \%$ in aerated and $11.58 \%$ and $15.71 \%$ in hypoxic condition, respectively. There is no statistically significant difference between cultivars in aerated condition. In contrast, more than twice additional aerenchyma formation was observed due to hypoxic condition in comparison to aerated condition. Results of cross-sectional method showed that middle portion of adventitious roots is the place that aerenchyma initiates to form, but well-developed aerenchyma was seen at about $80-90 \mathrm{~mm}$ behind the root apex (basal portion) under hypoxia. The results of root porosity of basal portion of adventitious roots of four sunflower cultivars (CMS14 $\times$ R-864 CMS51 $\times$ R-14, CMS19 $\times$ R- $\mathrm{N}_{1}-118$ and Hysun-33) showed higher amounts of root porosity in buoyancy method in comparison to cross-sectional method.
\end{abstract}

Keywords: aerenchyma, buoyancy method, cross-sectional method, Helianthus annus, hypoxia, root porosity

\section{Introduction}

Flooding is a worldwide stress factor which periodically affects different plants through reduction of oxygen concentration in rhizosphere (Armstrong et al. 1994). Depletion of oxygen concentration below physiological optimum results oxygen deficiency or hypoxia (Morard and Silvestre 1996) which in its turn induces a number of adaptive responses in molecular as well as whole plant level.

Aerenchyma formation in adventitious roots enhances root porosity which is the most important factor; because this morphological change reduces the resistance to the upward and downward gas flows and facilitates oxygen transport to the apical root zone by diffusion (Armstrong et al. 1994). As a result, the capacity of aerenchyma formation and establishment of adventitious roots (mostly near soil surface) can serve as a criterion for plant tolerance to hypoxia which it has been reported in a wide range of crop species such as wheat (Watkin et al. 1998), rice (Justin and Armstrong 1991), and maize (Gunawardena et al. 2001). There are two basic forms of aerenchyma: schizogeny which develops by the separation of cells (Laan et al. 1989), lysigeny which develops when cell walls degrade (Jackson 1989).

There are various methods to quantify the porosity of plant tissues; each one has its own merits and drawbacks. Choosing the most proper method for each experiment depends on the amount and structure of available plant materials (Visser and Bogemann 2003) as well as quantitative or qualitative goals. However best known and widely used methods are microscopical cross-sectional method and buoyancy method based on Archimedes' principle.

Microscopical cross-sectional is a simple technique which provides images of root anatomical structure (Armstrong 1993). Although this method has been

Ahmadi S, Mostajeran A, Shokrollahi S 2013 Comparing root porosity of sunflower adventitious root segments using cross-sectioning and buoyancy method under hypoxic condition. Plant Root 7: 12-20. doi:10.3117/plantroot.7.12 Copyrights 2013, Plant Root (JSRR), www.plantroot.org 
used for qualitative goals in a wide range of plants such as Luffa cylindrica (Shimamura et al. 2007), Juncus effusus (Visser and Bogemann 2006), maize (Drew et al., 1979), wheat (Trought and Drew 1980) and rice (Mostajeran and Rahimi-Eichi 2008), it needs a lot of work and time, and various factors can affect its reliability (Visser and Bogemann 2003). This method may not be suited for porosity measurement of fragile fresh tissues (Barber et al. 1962), tissues with none fully developed porosity (Canny and Huang 1993), and tissues that their anatomy changes within millimeters in vertical direction (Visser and Bogemann 2003).

Buoyancy method is a more convenient method based on the measurement of mass difference between intact and water infiltrated roots. When sufficient vacuum applied, water can fill all gas spaces in the root tissue, and the volume of the root air spaces can be calculated from the weight of this water. The main problem is that the weight of wet root tissue can simply be overestimated because of water that adheres to the surface when submerged in water (Videmšek et al. 2006). Raskin (1983) introduced a method based on Archimedes' principle -which is known as buoyancy method- and later this method was modified by Thomson et al. (1990). Buoyancy method has been used to evaluate root porosity in various plants such as Trifolium (Gibberd et al. 2001), wheat (Thomson et al. 1990), and Brassica napus (Voesenek and Blom 1999). The only drawback of this method is that this method needs a large amount of plant material (Visser and Bogemann 2003).

Previous researches have been shown that in sunflower plants, waterlogging can induce some adaptive responses (Kawase and Whitmoyer 1980). For example, over several minutes, ethylene production accelerates and stimulates aerenchyma formation in adventitious roots and induces the growth of these roots (Drew et al. 1979, Jackson 1989, Vartapetian and Jackson 1997). In sunflower adventitious roots, transduction of ethylene signal results in the death of some cortical cells and, as a consequence, causes formation of aerenchyma (Vartapetian and Jackson 1997). Therefore the rate of porosity and adventitious roots establishment in hypoxic condition is a circuit factor in sunflower tolerance. It has been reported that in hypoxic condition the aerenchyma formation in sunflower's adventitious roots increased in compare to aerated roots (Kawase 1979). However, there is no data about comparison between two methods as well as the anatomy changes that happen along individual roots. Although there is some information related to the root porosity of different segments of a single root, the amount of root porosity in different portions of sunflower adventitious roots is not reported. Therefore the objectives of this experiment are to evaluate the effect of hypoxic condition on adventitious root porosity and to measure the percentage of root porosity in different portion of adventitious roots by buoyancy and cross-sectional methods and compare their results.

\section{Materials and Methods}

\section{First Experiment: Evaluation of Root Porosity by Two Methods}

Seeds of two cultivars (CMS14 $\times$ R-864 and Hysun-33) of sunflower (Helianthus annus L.) were obtained from Institute of Seed Researches, Isfahan, Iran. Seeds were surface-sterilized with $70 \%$ ethanol for $15 \mathrm{~min}$ and $1 \%$ sodium hypochlorite for $2 \mathrm{~min}$, and then washed repeatedly with distilled water. Seeds were germinated on moistened filter paper in darkness at $25^{\circ} \mathrm{C}$ for 3 days. In order to select healthy and uniform seedling, they were transferred to little pots filled with peat and vermiculate (1:1) for 4 days and then uniform plants were transferred to special 4-liter containers filled with full strength Hoagland's solution. Plants were aerated continuously for two weeks and nutrient solution was renewed every 3 days. At day 14 ( $21^{\text {st }}$ growth day), 3 days of hypoxic condition applied to treated plants using $\mathrm{N}_{2}$ bubbling procedure (Kawase 1979). In contrast, control plants had sufficient oxygen according to statistical lay out. The experiment was set up in a completely randomized design with three replicates. All seedlings were grown at $25^{\circ} \mathrm{C}$ and an irradiance of 1500 Lux (using fluorescent lamp) for $16 / 8$ hours day/night. The plants were harvested for root porosity measurement as well as cross-section analysis at $24^{\text {th }}$ growth day.

\section{Oxygen Measurement}

The modified Winkler test (Clesceri et al. 2005) was used to determine the concentration of dissolved oxygen in control and hypoxic solutions. $2 \mathrm{~mL}$ of the manganous sulfate solution and $2 \mathrm{~mL}$ of the alkaline-potassium iodide-sodium azide solution was added at the surface of a $300 \mathrm{~mL}$ sample solution to form a white precipitate of $\mathrm{Mn}(\mathrm{OH})_{2}$. This precipitate was then oxidized by the dissolved oxygen in the solution sample into a brown manganese precipitate. In the next step, $1 \mathrm{~mL}$ of sulfuric acid was added to acidify the solution and converted the brown precipitate to a colorless solution. In a glass flask, $2 \mathrm{~mL}$ of starch solution was added to $200 \mathrm{~mL}$ of the solution sample and a blue color was formed. This solution was titrated by slowly dropping sodium thiosulfate solution from a calibrated pipette into the flask while it was continually stirred. Titration was slowly 
continued until the sample turned clear. The concentration of dissolved oxygen in the sample is equivalent to the number of milliliters of titrant used. Each $\mathrm{mL}$ of sodium thiosulfate added, equals $1 \mathrm{mg}$ $\mathrm{L}^{-1}$ dissolved oxygen. The dissolved oxygen was measured once a day for three days in control and hypoxic media with plant and the average was 5.92 and $1.94 \mathrm{mg} \mathrm{L}^{-1}$ for aerated and hypoxic solutions respectively.

\section{Root Porosity Estimation Using Buoyancy Method}

The root porosity was measured using Raskin (1983) method which was modified by Thomson et al. (1990). The adventitious roots were cut with a razor blade and gently blotted by rolling them on tissue paper to remove adherent water. Length of adventitious root samples (almost $10 \mathrm{~cm}$ ) was divided into three equal portions such as apical $(0-3 \mathrm{~cm})$, middle (3-6 $\mathrm{cm})$, and basal $(6-9 \mathrm{~cm})$ behind root apex. Then each portions of adventitious roots were separately weighed (FW). The fresh weight of each portion was almost higher than $0.2 \mathrm{~g}$ which is well sufficient for buoyancy method based on Visser and Bogemann (2003). Each portion of the adventitious roots was submerged in distilled water and weighed $\left(\mathrm{W}_{\text {sub }}\right)$. After this, the root samples were placed in tap water and vacuumed for $5 \mathrm{~min}$. This process was repeated at least three times and then root samples were submerged in water and weighed $\left(\mathrm{W}_{\text {inf }}\right)$. The adventitious root porosity was calculated using equation (1).

Porosity (\%; v:v) $=100 \times \frac{\text { Winf-Wsub }}{\text { FW-Wsub }}$

\section{Root Porosity Determination Using Cross-Sectional Method}

The roots of plant samples were washed and then fixed in $70 \%$ ethanol. The microscopic cross-sections were obtained from three portions of adventitious roots as described above. More than 50 root cross-sections were prepared from each portion. Cross-sections were lightened in $20 \%$ sodium hypochlorite solution for 3-5 $\mathrm{min}$ and then washed three times in distilled water. Then cross-sections were neutralized with 5\% acetic acid solution for one min, and washed repeatedly with distilled water. Finally, cross-sections were successively stained with $1 \%$ aqueous solutions of Methyl green and Karmene (Da Silva et al. 2003).

Picture of cross-sections were prepared using LM (Olympus microscope model BX-50). The area of air spaces was determined by analysis of 8 photographical images with sufficient thickness and resolution of each portion, then the result expressed as the average ratio of the area of root spaces to the total cross-sectional area of the root (\%; s:s) (Armstrong 1993).

Second Experiment: Comparison between Two Methods for Basal Portion

Seeds of four sunflower cultivars (CMS14 $\times$ R-864, Hysun-33, CMS19 $\times$ R-N -118 and CMS51 $\times$ R-14) were obtained from the Centre of Seed Researches, Isfahan, Islamic Rep. of Iran. Seeds were grown and treated same as the first experiment. Then, adventitious roots of four cultivars ( 8 replicates) were separated and only basal portions $(80-90 \mathrm{~mm}$ behind root apex) were used for root porosity measurements using buoyancy and cross-sectioning methods. $\mathrm{W}_{\text {inf, }}$, $\mathrm{W}_{\text {sub }}$ and FW measured for buoyancy method similar to above. Simultaneously, basal portion of adventitious roots were fixed, stained, photographed and analyzed as described above, for cross-sectional method. Eventually, the results of two methods were correlated and compared with 45 degree line for bios.

\section{Statistical Analysis}

The experiment was conducted in a completely randomized design with three replicates. Statistical analysis was carried out using SigmaStat 3.1 (Jandel Scientific Software) for ANOVA as well as Duncan's multiple-range test to compare the treatment means.

\section{Results}

\section{Root Porosity Using Buoyancy Method}

The mean porosity values $(\% ; \mathrm{v}: \mathrm{v})$ of three portions of adventitious roots in Hysun-33 and CMS14 $\times$ R-864 cultivars were $10.65 \%$ and $12.83 \%$ for aerated plants and $18.80 \%$ and $21.42 \%$ for hypoxic plants, respectively (Table 1 ). The result indicated that, the difference between root porosity of two cultivars in aerated condition is not statistically significant but in hypoxic condition the difference is significant. In contrast, a significant difference $(P<0.05)$ between root porosities of aerated and hypoxic plants was observed. Due to hypoxic condition, both cultivars show additional aerenchyma formation in compare to aerated plants $(79 \%$ and $66 \%$ more aerenchyma for Hysun-33 and CMS14 $\times$ R-864 cultivars, respectively).

Data in Table 1 show that in aerated plants there is no difference between root porosity of three portions of adventitious roots of Hysun-33 cultivar. However, different root portions of CMS14 $\times$ R-864 show statistically significant difference in aerated condition. In hypoxic condition, basal portion shows higher root 
Table 1. Root porosity (\%, v:v) of adventitious roots of sunflower cultivars under aerated and hypoxic conditions, using buoyancy method

\begin{tabular}{llllll}
\hline & Condition & \multicolumn{4}{c}{ Root portion } \\
\cline { 3 - 6 } & & apical & middle & basal & average \\
\hline \multirow{2}{*}{ Hysun-33 } & Aerated & $10.38^{*} \mathrm{~d}$ & $10.86 \mathrm{~d}$ & $10.71 \mathrm{~d}$ & $10.65 \mathrm{C}$ \\
& Hypoxic & $14.07 \mathrm{c}$ & $17.33 \mathrm{~b}$ & $25.00 \mathrm{a}$ & $18.80 \mathrm{~B}$ \\
& & & & \\
CMS 14 $\times$ R-864 & Aerated & $10.41 \mathrm{~d}$ & $12.42 \mathrm{c}$ & $15.66 \mathrm{~b}$ & $12.83 \mathrm{C}$ \\
& Hypoxic & $17.97 \mathrm{~b}$ & $19.61 \mathrm{~b}$ & $26.68 \mathrm{a}$ & $21.42 \mathrm{~A}$
\end{tabular}

*Data are means from six replicates. According to Duncan's multiple range test Values followed by same lower case letter within table are not significantly different $(P<0.05)$. The comparisons were preformed separately for the average values.
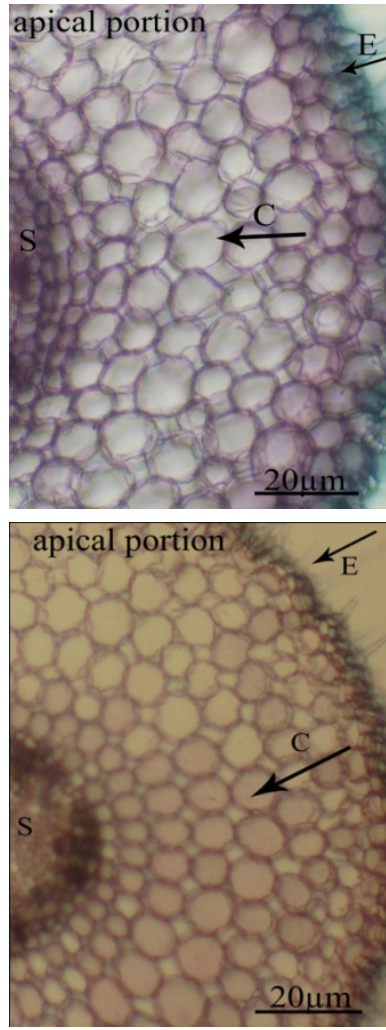
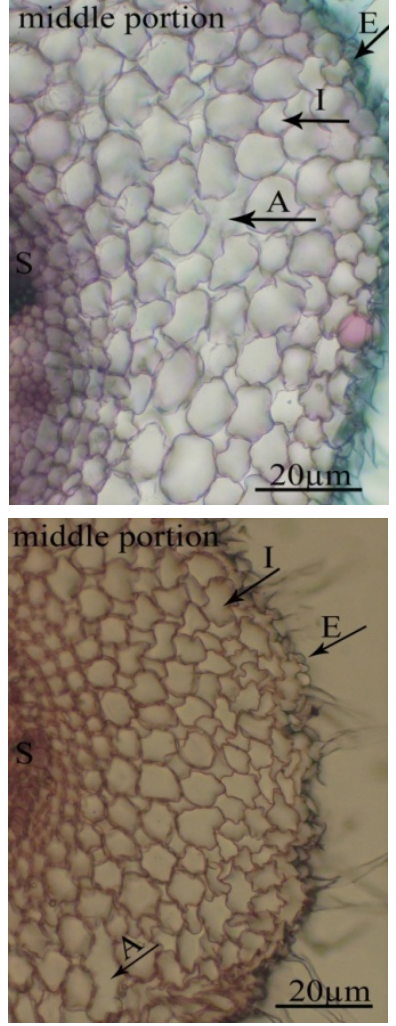
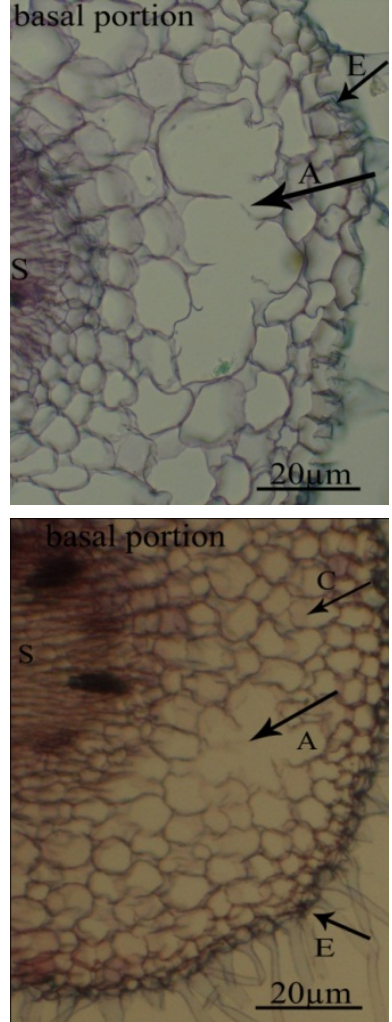

Fig. 1. Cross-sectional images of different portions (apical, middle and basal) of adventitious roots of CMS14 × R-864 (upper pictures) and Hysun-33 (lower pictures). Abbreviations: C, cortex cell; S, stele; A, aerenchyma; I, irregular shape cell; E, epidermis.

porosities and the difference is statistically significant in compare to middle portions. Simultaneously, there is no statistically significant difference between two similar root portions at apical (aerated), middle and basal (hypoxia) for two cultivars. In fact, the more distance far from the root apex, the more root porosity was observed.

\section{Root Porosity Using Microscopical Cross-sectional Method}

According to the pictures obtained from cross-sectional method (Fig. 1), after 3 days of hypoxia, both cultivars of sunflower show cell degradation in their root cortex, resulting in lysigenous aerenchyma formation. However the rate of aerenchyma formation was different in different root portion as well as different cultivar. In the apical portion of adventitious roots of hypoxic plants, close to the root tip (10-20 mm), aerenchyma was not detectable (Fig. 1 left). At the middle portion, cell wall degradation was evident (Fig. 1 middle) with 
Table 2. The ratio of root porosity (aerenchyma cross section to root cross- section, s:s\%) of adventitious roots of sunflower cultivars under aerated and hypoxic condition, using cross-sectional method

\begin{tabular}{llrrrr}
\hline & & \multicolumn{5}{c}{ Root portion } \\
\cline { 3 - 6 } Cultivar & Condition & \multicolumn{1}{c}{ apical } & middle & \multicolumn{1}{c}{ basal } & \multicolumn{1}{c}{ average } \\
\cline { 3 - 6 } & & & & & \\
\hline \multirow{2}{*}{ Hysun-33 } & Aerated & $4.21 * \mathrm{c}$ & $5.41 \mathrm{c}$ & $5.75 \mathrm{c}$ & $5.12 \mathrm{C}$ \\
& Hypoxic & $6.32 \mathrm{c}$ & $11.68 \mathrm{~b}$ & $16.75 \mathrm{~b}$ & $11.58 \mathrm{~B}$ \\
& & & & & \\
CMS 14 $\times$ R-864 & Aerated & $5.27 \mathrm{c}$ & $6.79 \mathrm{c}$ & $7.35 \mathrm{c}$ & $6.47 \mathrm{C}$ \\
& Hypoxic & $8.27 \mathrm{c}$ & $17.21 \mathrm{a}$ & $21.66 \mathrm{a}$ & $15.71 \mathrm{~A}$ \\
\hline
\end{tabular}

* Data are means from nine replicates. According to Duncan's multiple range test Values followed by same lower case letter within table are not significantly different $(P<0.05)$. The comparisons were preformed separately for the average values.

irregular-shaped cells that entered the process of lysigenous aerenchyma formation. The crosssectional images were obtained from different portions of the adventitious roots indicated that more mature part of the roots i.e. basal portion shows more developed aerenchyma in hypoxic condition (Fig. 1 right).

The calculated root porosity ratio (aerenchyma area to root cross-sectional area, \%; s:s) of three portions of adventitious roots using cross-sectional images has been shown in Table 2 . The average root porosity of Hysun-33 and CMS14 $\times$ R-864 cultivars are $5.12 \%$ and $6.47 \%$ in aerated and $11.58 \%$ and $15.71 \%$ in hypoxic condition, respectively. There is no significant difference between two cultivars in aerated condition. In contrast, there is a statistically noticeable difference between aerobically and hypoxicaly grown plants. Both cultivars show more than twice additional aerenchyma formation due to hypoxic condition in compare to aerated condition. Different root portions in different cultivars show different reaction to hypoxic condition. Data in Table 2 shows that in aerated condition there is no difference between root porosity of three portions of adventitious roots. Controvertibly, among treated plants there is a significant difference between three portions of roots in each cultivar and root porosity increases by distance from the root apex. Simultaneously, there is statistically significant difference between root porosity of two cultivars in middle and basal portions due to hypoxia.

\section{Comparison between Two Methods for Three Root} Portions

Although data obtains from both buoyancy and cross-sectional methods (Table 1 and 2) indicated that there are no significant differences between root porosities of different portions of different cultivars in aerated condition, the magnetite of the result is different in two methods. Higher amount of root porosities are calculated by buoyancy method i.e. $10.65 \%$ and $12.83 \%$ in average in compare to $5.12 \%$ and $6.47 \%$ which obtained from cross-sectional method for Hysun-33 and CMS14 $\times$ R-864 cultivars, respectively. The differences of two methods are less obvious in hypoxic condition for Hysun-33 and CMS14 $\times$ R-864 cultivars, respectively i.e. $18.8 \%$ and $21.42 \%$ versus $11.58 \%$ and $15.71 \%$ which obtained from buoyancy and cross-sectional method. The interaction effect of hypoxic condition on evaluation of root porosity using different methods could be seen in different cultivars (Fig. 2). The variation in root porosity in different methods in different cultivars gets increase by distance from the root apex to base. The additional root porosity (\%) in buoyancy method versus cross-sectional method in three root portions gives additional information. Data in Table 3 indicated that in average $122.0 \%, 91.8 \%$ and $99.0 \%$ more root porosities have been obtained for apical, middle and basal portions of adventitious roots of aerated plants in buoyancy method in compare to cross-sectional method. Higher value for root porosity is also seen especially in apical portion $(119.9 \%)$ using buoyancy method in hypoxic plants. Nevertheless, these two methods show less deviation for middle and basal portions i.e. $31.2 \%$ and $36.2 \%$, respectively. These results indicated that less root poros ities in apical portion compare to basal portion resulted higher overestimation for root porosity.

\section{Comparison Between Two Methods For Basal Portion}

In the first experiment, cross-sectional images which obtained from basal portion of adventitious roots 
Table 3. Additional root porosities (\%) using buoyancy method versus cross-sectional method for different root segments of sunflower cultivars under aerated and hypoxic condition

\begin{tabular}{lccccccc}
\hline \multirow{2}{*}{ Cultivar } & \multicolumn{3}{c}{ Aerated } & & \multicolumn{3}{c}{ Hypoxic } \\
\cline { 2 - 3 } \cline { 6 - 8 } & apical & middle & basal & & apical & middle & basal \\
\hline Hysun-33 & 146.6 & 100.7 & 84.9 & & 122.6 & 48.4 & 49.3 \\
CMS14 $\times$ R-864 & 97.5 & 82.9 & 113.1 & & 117.3 & 13.9 & 23.2 \\
Average & 122.0 & 91.8 & 99.0 & & 119.9 & 31.1 & 36.2 \\
\hline
\end{tabular}

showed fully developed aerenchyma in hypoxic condition (Fig. 1). In addition, in buoyancy method, root porosity of basal portion of hypoxic adventitious roots has statistically significant difference in compare to other two portions (Table 1). Therefore, basal portion of hypoxic plants' adventitious roots was used in the second experiment to quantitatively compare the root porosity in buoyancy method and cross-sectional method.

Data obtained from the second experiment as well as the result of the first experiment (Table 3) show that root porosities of basal portion which calculated by buoyancy method are higher than those which obtained from cross-sectional image analysis. The low correlation coefficient for cross-sectioning versus buoyancy method $\left(R^{2}=0.429\right)$ shows high variation between two methods for four cultivars. Root porosity of basal portion of hypoxic plant's adventitious roots obtained by buoyancy method and cross sectional image analysis plotted on a 45 degree angle line (Fig. 3). The deviation between fitted line and 45 degree angle line indicated the variation as well as lower estimation of cross sectional method compare to buoyancy method in different cultivars. A noticeable point in Figure 3 is that root porosity variation in horizontal axis is wider than vertical axis. In other word, data which has been obtained for each cultivar is more deviated in cross-sectional method rather than buoyancy method.

The differences in root porosities within different cultivars as well as different methods are presented in Figure 4. The lowest and the highest root porosities in cross-sectional and buoyancy method were belonged to CMS51 $\times$ R-14 $(12.62 \%$ and $14.37 \%)$ and CMS19 $\times$ R-N1-118 (24.08\% and 30.50\%) cultivars, respectively.

\section{Discussion}

Short-term of hypoxia may lead to a long-term of morphological adaptations (Geigenberger 2003) such as developing aerenchyma and adventitious root formation (Drew et al. 2000, Malik et al. 2003, Gunawardena et al. 2001). A number of studies show that aerenchyma formation and additional root porosity are positively associated with plant tolerance
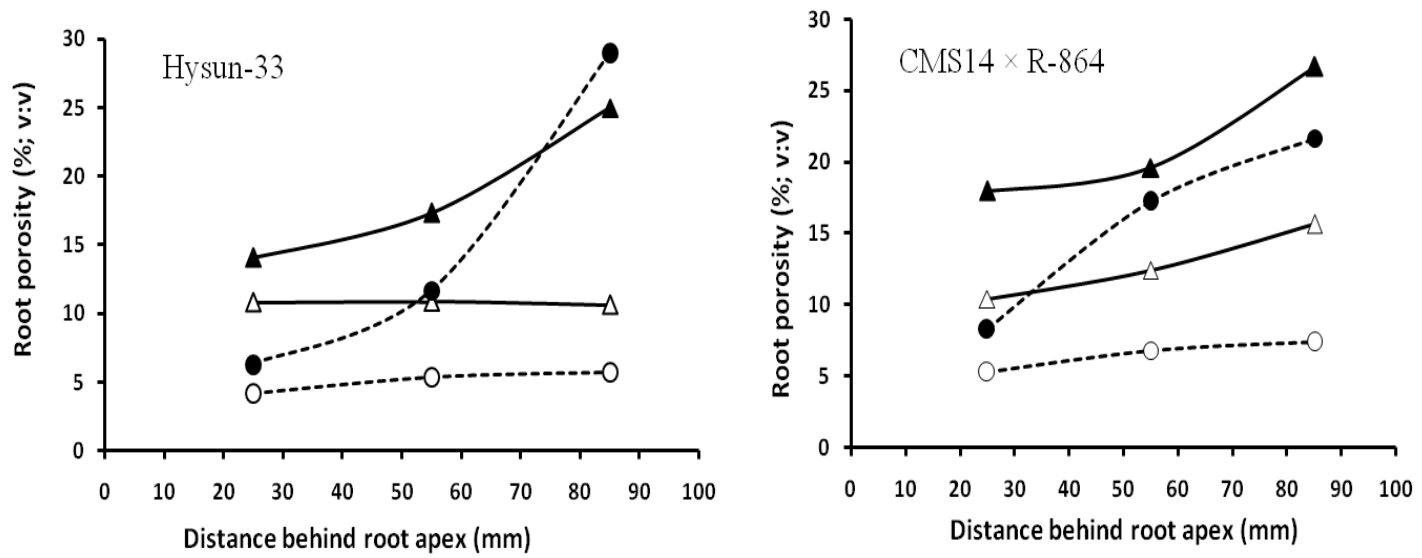

Fig. 2. Root porosities calculated using buoyancy method (solid lines) and cross-sectional method (dot lines). Hollow marks and solid marks are used for aerated and hypoxic plants, respectively. 


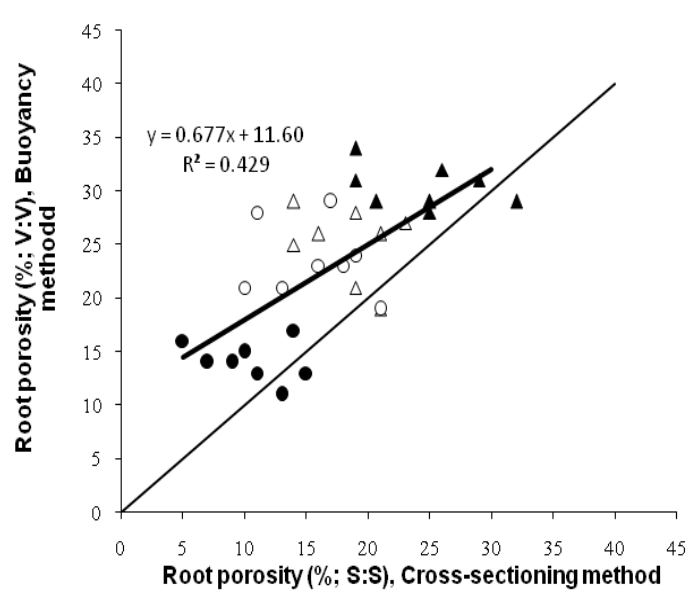

Fig. 3. Comparison between root porosity of basal portion of adventitious roots using cross-sectional (\%; s:s) and buoyancy $(\% ; \mathrm{v}: \mathrm{v})$ methods under hypoxic condition $(8$ replicates). Roots were taken from $80-90 \mathrm{~mm}$ distance behind root apex of CMS51 $\times$ R-14 (solid circles), Hysun-33 (hollow circles), CMS19 $\times$ R-N1-118 (solid triangles) and CMS14 $\times$ R-864 (hollow triangles) cultivars. The diagonal line indicates a theoretical 1:1 correlation $\left(\mathrm{R}^{2}=0.429\right)$.

capacity to hypoxia, and tolerance to hypoxia can be directly related to ventilation efficiency which is acquired through the development of air spaces within the tissue (Justin and Armstrong 1991). Our study indicates that short period of hypoxia (3 days) caused a significant increase in the root porosity of four sunflower cultivars. These results are similar to what has been observed in different crops such as maize (Gunawardena et al. 2001), wheat (Watkin et al. 1998), Trifolium subterraneum (Aschi-Smiti et al. 2003), sunflower (Kawase 1979) and rice (Justin and Armstrong 1991).

Although a difficulty of using cross-sectional method for root porosity estimation is the quality of microscopic slices, in this experiment only slices with less thickness and sufficient quality (Videmšek et al. 2006) were used for image analysis. However, the major issue for cross sectional method is the best distance for taking slices. For maize as a model plant for assessing root porosity, different results have led to a controversial conclusion, Bouranis et al. (2003) found air channels $2 \mathrm{~mm}$ behind the root tip, Gunawardena et al. (2001) at $10 \mathrm{~mm}$ behind the tip, and Malik et al. (2003) in the zone $20 \mathrm{~mm}$ behind the apex. The ambiguous interpretation of proper distance for cross-sectioning, in addition to lack of information about root porosity changes along the adventitious roots for different cultivars of sunflower make it impossible to compare our results with others. In our study root cross-sections were taken at three different portions as apical, middle and basal portions

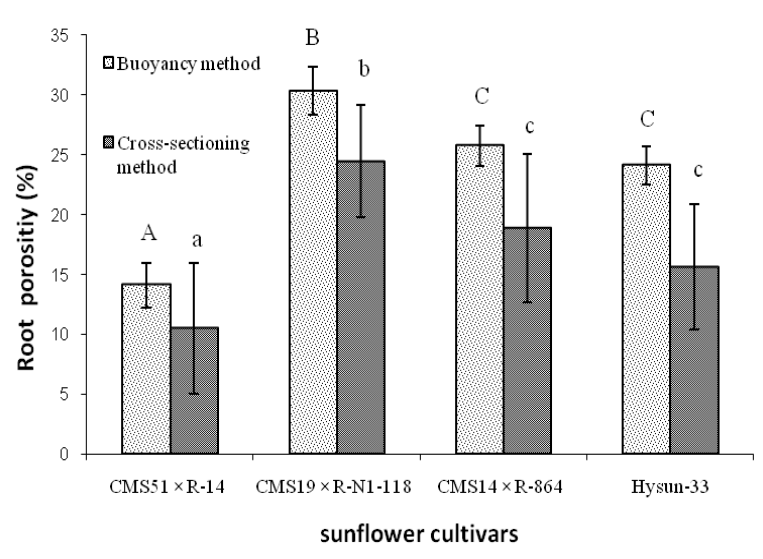

Fig. 4. Root porosity (\%) of basal portions of different sunflower cultivars using buoyancy and cross-sectional method. Vertical error bars show SD. Different letters (capital letters for buoyancy method and lower case letters for cross-sectional method) indicates significant difference between mean values according to Duncan's multiple range test with $95 \%$ confidence interval $(n=8)$.

behind the root tip. Our results indicated that middle portion is the place that aerenchyma initiates to form, so this part is suitable for surveying initial events of aerenchyma formation in sunflower. Simultaneously, well-developed aerenchyma at about $80-90 \mathrm{~mm}$ behind the root apex indicated that basal portion is the best part of the adventitious root for measuring root porosity in sunflower (Fig. 1). It should be considered that the accuracy of estimations could have been improved if the morphology of root tissues had been studied at several distances from the apex (Videmšek et al. 2006). Our result showed that using cross-sectional method may easily lead to relatively large standard deviations of the mean (Fig. 4). This might be due to difficulties in slice preparation and the interpretation of the photographs of the cross-sections, particularly in tissue with developing aerenchyma (Fig. 1, apical and middle portions). This is a general difficulty in cross sectional method. However, in the second experiment that just basal portions of adventitious roots with fully developed aerenchyma were used, these variations were existed consistently. Therefore, it can be concluded that a possible reason for this can be this fact that the pathway of gas-spaces along the root length is not similar to a pipe with equal radius; so the cross-sections may varied by chance from a location with lower or higher radius.

Buoyancy method, except of thin and light apical portions, resulted in more precise data and did not have cross-sectional method difficulties. However, for apical portions there were relatively large 
amounts of deviations between different replicates (Fig. 3). One reason for this deviation may be this fact that difference between $\mathrm{W}_{\text {inf }}$ and $\mathrm{W}_{\text {sub }}$ is very small and a sensitive microbalance with 4 digits is used for measuring this difference which in its turn may results into non avoidable errors due to very small disturbance in air. In addition, Visser and Bogemann (2003) previously showed effects of sample weight on the accuracy of porosity measurement with the buoyancy method and found that below 100-200 $\mathrm{mg}$ this method resulted in less reliable data, and average porosity of small $(50 \mathrm{mg})$ samples deviated considerably from those of the larger samples.

In the first experiment, comparing the values obtained from hand-sectioning with those obtained from buoyancy measurements (Table 3 ) showed that the values obtained by buoyancy method are higher than those obtained by cross-section method for all three portions of adventitious roots. Overestimation was more significant in apical portion (Table 3). Cross-sectioning images showed that in apical portion there are no distinguishable cavities among cells. Similarly, in the second experiment, overestimation of buoyancy method in compare to cross-sectional method was seen for basal portions of adventitious roots with fully developed aerenchyma. This means that it should be specific reasons for this over-estimation. We suggest that it may have been due to this fact that in buoyancy method all small and big sizes of spaces exposed to vacuum and affects the result, whereas most of very small spaces between cells are ignored in cross-sectional method.

For sunflower plants sufficient root material is available, therefore buoyancy method can easily be used for measuring root porosity. Cross-sectional method is suitable to study the anatomy of the intercellular gas spaces and aerenchyma formation but as a porosity measurement tool, it needs a lot of cross-sections per unit length of root to consider as a reliable method.

\section{Acknowledgments}

Special thanks to the University of Isfahan for financial support and also department of biology for laboratory space and facilities. Thanks to Dr. F. Zarrinkamar (University of Tarbiat-Modarres) and S. Allahyari (University of Isfahan) for their support and help in root sampling.

\section{References}

Armstrong W 1993 Methods of comparative studyaerenchyma, intercellular gas-space and aeration. In: Hendry GAF, Grime JP, Eds., Methods in comparative plant ecology (A laboratory manual). Chapman \& Hall,
London, New York, pp. 29-32.

Armstrong W, Brandle R, Jackson MB 1994 Mechanisms of flood tolerance in plants. Acta Bot. Neerl. 43: 307-358.

Aschi-Smiti S, Chaïbi W, Brouquisse R, Bérénice-Ricard B, Saglio P 2003 Assessment of enzyme induction and aerenchyma formation as mechanisms for flooding tolerance in Trifolium subterraneum 'Park'. Ann. Bot. 91: 195-204.

Barber DA, Ebert M, Evans NTS 1962 The movement of $\mathrm{O}^{15}$ through barley and rice plants. J. Exp. Bot. 13: 397-403.

Bouranis DL, Chorianopoulou SN, Siyiannis VF, Protonotarios VE, Hawkesford MJ 2003 Aerenchyma formation in roots of maize during sulphate starvation. Planta 217: 382-391.

Canny MJ, Huang CX 1993 What is in the intercellular spaces of roots? Evidence from the cryo-analytical-scanning electron microscope. Physiol. Plant. 87:561-568.

Clesceri LS, Rice EW, Greenberg AE 2005 Oxygen measurement. In: Eaton AD, Franson MAH, Eds., Standard methods for the examination of water and wastewater. 21st edition. American Public Health Association, Washington, pp. 456-498.

Da Silva S, De Castro EM, Soares AM 2003 Effects of different water regimes on the anatomical characteristics of root of grasses promising for regeneration of areas surrounding hydroelectric reservoirs. Cienc. Agrotec. 27: 393-397.

Drew MC, Jackson MB, Giffard S 1979 Ethylene promoted adventitious rooting and cortical air space (aerenchyma) in roots may be adaptive responses to flooding in Zea mays L. Planta 147:83-88.

Drew MC, He CJ, Morgan PW 2000 Programmed cell death and aerenchyma formation in roots. Trends Plant Sci. 5: 123-127.

Geigenberger P 2003 Response of plant metabolism to too little oxygen. Curr. Opin. Plant Biol. 6: 247-256.

Gibberd MR, Gray JD, Cocks PS, Colmer TD 2001 Waterlogging tolerance among a diverse range of Trifolium accessions is related to root porosity, lateral root formation and 'aerotropic rooting'. Ann. Bot. 88: 579589.

Gunawardena AHLA, Pearce DM, Jackson MB, Hawes CR, Evans DE 2001 Characterisation of programmed cell death during aerenchyma formation induced by ethylene or hypoxia in roots of maize (Zea mays L.). Planta 212: 205-214.

Jackson MB 1989 Regulation of aerenchyma formation in roots and shoots by oxygen and ethylene. In: Osborn DJ, Jackson MB, Eds., Cell separation in plants. Springer-Verlag. Berlin. Heidelberg, Germany, pp. 263274.

Justin SHFW, Armstrong W 1991 Evidence for the involvement of ethene in aerenchyma formation in adventitious roots of rice (Oryza sativa). New Phytol. 118: $49-62$.

Kawase M 1979 Role of cellulase in aerenchyma development in sunflower. Am. J. Bot. 66: 183-190.

Kawase M, Whitmoyer RE 1980 Aerenchyma development in waterlogged plants. Am. J. Bot. 67: 18-22.

Laan P, Smolders A, Blom C, Armstrong W 1989 The relative roles of internal aeration, radial oxygen losses, iron exclusion and nutrient balances in flood tolerance of Rumex species. Acta Bot. Neerl. 38: 131-145.

Malik AI, Colmer TD, Lambers H, Schortemeyer M 2003 Aerenchyma formation and radial $\mathrm{O}_{2}$ loss along adventitious roots of wheat with only the apical root 
portion exposed to $\mathrm{O}_{2}$ deficiency. Plant Cell Environ. 26: $1713-1722$

Morard E, Silvestre J 1996 Plant injury due to oxygen deficiency in the root environment of soil-less culture: A review. Plant Soil 184: 243-254.

Mostajeran A, Rahimi-Eichi V 2008 Drought stress effects on root anatomical characteristics of rice cultivars. Pak. J. Biol. Sci. 18: 2173-2183.

Raskin I 1983 A method for measuring leaf volume, density, thickness, and internal gas volume. HortScience 18: 698699.

Shimamura S, Yoshida S, Mochizuki T 2007 Cortical aerenchyma formation in hypocotyl and adventitious roots of Luffa cylindrica subjected to soil flooding. Ann. Bot. 100: 1431-1439.

Thomson CJ, Armstrong W, Waters I, Greenway H 1990 Aerenchyma formation and associated oxygen movement in seminal and nodal roots of wheat. Plant Cell Environ. 13: 395-403.

Trought MCT, Drew MC 1980 The development of waterlogging damage in young wheat plants in anaerobic solution culture. J. Exp. Bot. 31: 1573-1580.

Vartapetian BB, Jackson MB 1997 Plant adaptations to anaerobic stress. Ann. Bot. (Suppl. A), 79: 3-20.

Videmšek U, Turk B, Vodnik D 2006 Root aerenchyma - formation and function. Acta Agr. Slov. 87: 445 - 453.

Visser EJW, Bogemann GM 2003 Measurement of porosity in very small samples of plant tissue. Plant Soil 253: 81-90.

Visser EJW, Bogemann GM 2006 Aerenchyma formation in the wetland plant Juncus effusus is independent of ethylene. New Phytol. 171: 305-314.

Voesenek LACJ, Blom CWPM 1999 Stimulated shoot elongation- a mechanism of semi-aquatic plants to avoid submergence stress. In: Lerner HR, Ed., Plant responses to environmental stresses from phyto-hormones to genome reorganization. Marcel Decker. New York, pp. 431-448.

Watkin ELJ, Campbell CJ, Greenway H 1998 Root development and aerenchyma formation in two wheat cultivars and one Triticale cultivar grown in stagnant agar and aerated nutrient solution. Ann. Bot. 81: 349-354.

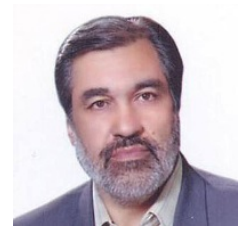

Dr. Akbar Mostajeran's research interest is focused on water relations of plants and also plant-microorganism relations mostly in drought condition. 